\title{
BENZİN VE GAZ YAKITLAR İÇİN YAĞ FİLMİ KAYNAKLI HC EMİSYONLARININ MATEMATİK MODELLENMESİ
}

\author{
M. İhsan Karamangil ${ }^{2}$, Seçkin Yenice ${ }^{1}$, Ömer Kaynaklı $^{1}$, Ali Sürmen ${ }^{3}$ \\ ${ }^{1}$ Uludag University, Faculty of Engineering and Architecture, Dept. of Mechanical Eng., Bursa \\ ${ }^{2}$ Uludag University, Faculty of Engineering and Architecture, Dept. of Automotive Eng., Bursa \\ ${ }^{3}$ Bursa Technical University, Rector \\ ihsan@uludag.edu.tr, seckinyenice@hotmail.com, kaynakli@uludag.edu.tr; $\underline{\text { ali.surmen@btu.edu.tr }}$
}

(Geliş/Received: 08.05.2012; Kabul/Accepted: 27.02.2014)

\section{ÖZET}

Silindir cidarları üzerindeki yağ filmi motor çıkış hidrokarbon (HC) emisyonlarının ana kaynaklarından birisi olarak bilinmektedir. Bu çalışmada, benzin, LPG ve metan için yağ filmi içerine emilen/salınan yakıt miktarı için matematik bir model geliştirilmiştir. Yağ filmi tarafından emilen/salınan LPG ve metanın benzinden daha düşük seviyede olduğu görülmüştür. Bu farklılığın en önemli parametresi çözünürlükle ilgili olan Henry sabiti olduğu tespit edilmiştir. Düşük motor devirlerinde yağ filmi yakıt buharı etkileşimine daha uzun süre tanındığı için emilen/salınan HC miktarları artmıştır. Artan sıkıştırma oranı ve giriş basıncı ile birlikte emilen/salınan HC miktarları artmıştır.

Anahtar kelimeler: Yağ filmi, Henry kanunu, HC emisyonları, Buji ateşlemeli motor

\section{MATHEMATICAL MODELING OF HC EMISSIONS RELEASED by OIL FILM for GASOLINE and GASEOUS FUELS}

\begin{abstract}
Oil film on cylinder liner has been suggested as a major source of engine-out hydrocarbon emissions. In this study, a mathematical modeling for the rate of absorption/desorption of the fuel in the oil film has been developed for gasoline, LPG and methane. It was seen that the absorption/desorption mechanism of LPG and methane into the oil film were lower than gasoline. It was determined that the most dominant parameter of this difference was Henry's constant, which was related to solubility. As interaction time of oil film-fuel vapor was longer at low engine speeds, the quantities of $\mathrm{HC}$ absorbed/desorbed increased. The quantities of $\mathrm{HC}$ absorbed/desorbed increased with increasing inlet pressure and compression ratio.
\end{abstract}

Keywords: Oil film, Henry's Law, HC emission, SI engine

\section{GÍRISŞ (INTRODUCTION)}

Silindir cidarları üzerinde yağ filminin temel görevi segmanları ve piston eteğini yağlamak, sürtünmeyi ve aşınmayı azaltmaktır. Birkaç mikron kalınlığındaki bu yağ filmi, emme, sıkıştırma ve yanma işlemleri sırasında hidrokarbon emme (absorbtion), genişleme ve egzoz stroklarında ise hidrokarbon salma (desorbtion) yeteneğine sahiptir. Motor çıkış hidrokarbon emisyonlarının \%10-25'inin yağ filminden emilen ve salınan hidrokarbonlardan kaynaklandığı tahmin edilmektedir, [1].
Dwyer-Joyce ve ark. [2] tek silindirli bir motor üzerinde yağ filmi kalınlığını belirlemek için bir düzenek kurmuşlar ve piston eteği civarındaki yağ filmi kalınlığını 2-21 $\mu$ m olarak ölçmüşlerdir. Baba ve ark. [3] piston eteği üzerindeki yağ filmi davranışını (kalınlık ve hız) incelemişlerdir. Dhar ve ark. [4] bir motor simülatöründe piston segmanı-silindir gömleği arasındaki yağ filmi kalınlığını belirlemeye çalışmışlar ve yă̆ filmi kalınlığını 3 farklı noktada 0,2-8 $\mu \mathrm{m}$ arasında ölçmüşlerdir. Kato ve ark. [5] piston eteği ile silindir gömleği arasındaki boşluğun yağ filmi kalınlığı ve hızında etkili olduğunu 
bulmuşlardır. Piston eteği ile silindir gömleği arasında 30-100 $\mu \mathrm{m}$ arasında boşluklar tespit etmişlerdir.

Korematsu [6] buji ateşlemeli bir motorda yă̆ filmi içerisine yakıt emiliminin yanmamış $\mathrm{HC}$ emisyonları üzerindeki etkisini incelemiştir. İnce yă filmi içerisine yakıt emilim ve salınım işlemini modellemiştir. Yağ filminden neşredilen yanmamış HC miktarının yă filminin pozisyonuna, motor devrine, difüzyon katsayısına, yağ filmi kalınlığına, çevrim sayısına ve motor yağı içerisindeki başlangıç yakıt konsantrasyonuna bağlı olduğunu bulmuştur.

Shenghua ve ark. [7] buji ateşlemeli motorlarda silindirlerdeki yağ filminin $\mathrm{HC}$ emisyonlarına olan etkisini incelemişlerdir. Yağlı ve yağsız yapılan deneyler sonucunda yağ filminin toplam HC emisyonları üzerindeki katkısını $\% 28$ olarak bulmuşlardır.

Yu ve ark. [8] buji ateşlemeli bir motorda yăg filmi içerisine yakıt emilim/salınım işleminin dinamik davranışı üzerine çalışmışlardır. Emilme/salınma olayı üzerinde en etkili parametrenin Henry sabiti olduğunu tespit etmişlerdir. Yine silindirlerin üst kısımlarında yer alan yağ filminin alt kısımdakilere göre emilme/salınma işlemine daha fazla katıldığını söylemektedirler. Yu ve Min [9] benzer bir çalışmada motor devri, motor yükü ve yağ filmi sıcaklığına bağlı parametrik bir çalışma yapmışlar ve çözünürlükle ilgili olan Henry sabitini yağ filmi içerisindeki yakıtın emilim ve salınım olayında en baskın parametre olarak göstermişlerdir.

Bu çalışmada yukarıda özetlenen çalışmalardan farklı olarak benzin ile gaz yakıtların yağ filmi kaynaklı HC emisyonları karşılaştırılmış ve sonuçlar bazı motor konstrüktif ve çalışma parametrelerine bağlı olarak incelenmiştir.

\section{MATEMATIK MODEL (MATHEMATICAL MODEL)}

Bu çalışmada, benzinli motorlarda farklı yakıtlar için yağ filminden kaynaklanan hidrokarbon emisyonlarının tespiti için matematik bir model geliştirilmiştir. Model iki alt kısımdan oluşmaktadır.

1. Termodinamik model

2. Yağ filmi kaynaklı HC oluşum modeli

Termodinamik modelde, seçilen motora ait geometrik özellikler ile kullanılan yakıt-hava karışımı tanımlanmıştır. Silindir içindeki gazların özgül ısıları, viskoziteleri, basınç ve sıcaklık değerleri her bir krank açısı adımında hesap edilmiştir. Ayrıca silindir içindeki 1S1 transferi, 1sı taşınım katsayısı, yanma sonucu oluşan ürünlerin miktarları yine krank açısına bağlı olarak bulunmuştur. $\mathrm{Bu}$ model $[10,11]$ nolu kaynaklarda detaylı olarak verildiği için burada izah edilmeyecektir. Bununla birlikte, bu makalelerde bahsedilen modellemelere aşağıdaki eklemeler yapılmıştır. Hem benzinin hem de gaz yakıtların silindir dışında karışım oluşturduğu düşünülmüş ve buna bağlı olarak gaz yakıtlarla çalışmada yakıtın kimyasal formülünden kaynaklanan volumetrik verim kaybı (yakıt buharının havanın yerini alması) hesaplanmıştır. Hesaplanan değerler $\eta_{\mathrm{v} 1}$ ile gösterilmiştir. Benzinin buharlaşması sırasında ortamı soğutma etkisi dikkate alınarak gaz yakıtlarda gerçekleşmeyen volumetrik verim artış1 $\eta_{\mathrm{v} 2}$ ile temsil edilmiştir. Son olarak burada $2000 \mathrm{~d}$ /dak'da tam yükte çalışma durumunda her üç yaktın aynı şartlarda silindir içine alındığı kabul edilerek volumetrik verimleri $\eta_{\mathrm{v} 3}=0,85$ olarak alınmıştır. Nihai volumetrik verim bu 3 etki dikkate alınarak hesaplanmış ve $\eta_{\mathrm{v}}$ ile gösterilmiştir. Buna göre hesaplanan değerler bir tablo halinde Tablo 1'de verilmiştir.

Tablo 1. Benzin, LPG ve metan için hesaplanan volumetrik verim $\left(\eta_{\mathrm{v}}\right)$ ile silindir içine alınan yakıt ve hava miktarları [12] (Volumetric efficiency calculated and fuel and air quantities entered to the cylinder for gasoline, LPG and methane)

\begin{tabular}{|c|c|c|c|}
\hline & $\begin{array}{c}\text { IZO-OKTAN } \\
\mathrm{C}_{8} \mathrm{H}_{18}\end{array}$ & $\begin{array}{c}\text { LPG } \\
\mathbf{C}_{3,7} \mathbf{H}_{9,4}\end{array}$ & $\begin{array}{c}\text { METAN } \\
\text { CH }_{4}\end{array}$ \\
\hline$\eta_{\mathrm{v} 1}$ & 0,9835 & 0,9664 & 0,905 \\
\hline$\eta_{\mathrm{v} 2}$ & 1,0142 & 1 & 1 \\
\hline$\eta_{\mathrm{v} 3}$ & 0,85 & 0,85 & 0,85 \\
\hline$\eta_{\mathrm{v}}$ & 0,8478 & 0,8214 & 0,7693 \\
\hline$\rho_{\text {yak }}\left(\mathrm{kg} / \mathrm{m}^{3}\right)$ & 4,672 & 2,204 & 0,655 \\
\hline$\rho_{\mathrm{krsm}}\left(\mathrm{kg} / \mathrm{m}^{3}\right)$ & 1,214 & 1,191 & 1,109 \\
\hline $\begin{array}{c}\text { Stokimetrik } \\
\mathrm{H} / \mathrm{Y} \text { oran1 } \\
(\mathrm{kgH} / \mathrm{kgY})\end{array}$ & 15,06 & 15,44 & 17,17 \\
\hline $\mathrm{m}_{\mathrm{h}}(\mathrm{kg})$ & $3,872.10^{-4}$ & $3,752.10^{-4}$ & $3,514.10^{-4}$ \\
\hline $\mathrm{m}_{\mathrm{y}}(\mathrm{kg})$ & $2,571.10^{-5}$ & $2,429.10^{-5}$ & $2,047.10^{-5}$ \\
\hline $\mathrm{m}_{\text {atk }}(\mathrm{kg})$ & $7,877.10^{-7}$ & $7,877.10^{-7}$ & $7,877.10^{-7}$ \\
\hline $\mathrm{m}_{\mathrm{dolgu}}(\mathrm{kg})$ & $4,137 \cdot 10^{-4}$ & $4,002.10^{-4}$ & $3,726.10^{-4}$ \\
\hline
\end{tabular}

Burada $\rho_{\text {yak }}$ ve $\rho_{\text {krsm: }}$ buhar fazındaki yakıtın ve karışımın yoğunluğunu, $m_{h}$ ve $m_{y}$ : silindir içine alınan

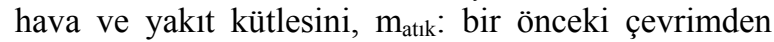
silindir içinde kalan atık gaz miktarını, $\mathrm{m}_{\text {dolgu }}$ : silindir içindeki toplam kütleyi $\left(\mathrm{m}_{\mathrm{h}}+\mathrm{m}_{\mathrm{y}}+\mathrm{m}_{\mathrm{atık}}\right)$ temsil etmektedir.

Yağ filmi kaynaklı HC oluşum modelinde, Henry ve difüzyon kanunlarını kullanarak, yakıtın yağ filmi içine kütlesel emilme/salınma hızının etkisi benzin, LPG ve metan için motor devrine, sıkıştırma oranına, giriş basıncına, hava fazlalık katsayısına göre incelenmiştir. Silindir içine alınan yakıt miktarları her yakıt için stokimetrik oranda tutulmuştur. Motora ait geometrik özellikler ve çalışma parametreleri ile sayısal çözümde kullanılan yağ filmi özellikleri Tablo 2'de verilmiştir. 
Tablo 2. Motora ait geometrik özellikler, çalışma şartları ve yağ filmi özellikleri (Geometry of model engine and operating conditions and oil film properties)

\begin{tabular}{|c|c|}
\hline S1k1ştırma oranı & 8,3 \\
\hline Silindir çap1 & 0,0864 \\
\hline Strok $(\mathrm{m})$ & 0,0674 \\
\hline Biyel uzunluğu (m) & 0,13 \\
\hline Krank yarıçapı $(\mathrm{m})$ & 0,0337 \\
\hline Kompresyon hacmi $\left(\mathrm{m}^{3}\right)$ & $5,41 \times 10^{-5}$ \\
\hline Strok hacmi $\left(\mathrm{m}^{3}\right)$ & $3,95 \times 10^{-4}$ \\
\hline Motor devri (d/dak) & 2000 \\
\hline Giriş basınc1 (bar) & 1 \\
\hline Hava fazlalık katsayısı & 1 \\
\hline Emme supabı açılma açısı & $10^{\circ} \mathrm{BTDC}$ \\
\hline Emme supabı kapanma açısı & $34^{\circ} \mathrm{ABDC}$ \\
\hline Egzoz supabı açılma açısı & $31^{\circ} \mathrm{BBDC}$ \\
\hline Egzoz supabı kapanma açısı & $55^{\circ}$ ATDC \\
\hline Ateşleme avans1 & $-25^{\circ} \mathrm{BTDC}$ \\
\hline Yanma süresi & $70^{\circ}$ \\
\hline Yağ filmi kalınlığ $(\mu \mathrm{m})$ & 3 \\
\hline $\begin{array}{l}\text { Referans sıcaklıktaki yağ } \\
\text { yoğunluğu }\left(\mathrm{kg} / \mathrm{m}^{3}\right)\end{array}$ & 894 \\
\hline $\begin{array}{l}\text { Motor yağı moleküler ağırlığ } 1 \\
(\mathrm{~kg} / \mathrm{kmol})\end{array}$ & 420 \\
\hline
\end{tabular}

\subsection{Yağ Filmi Kaynaklı HC Oluşum Modeli (HC} Absorbtion/Desorbtion Model by Oil Film)

Bir buji ateşlemeli motorda yağ filmi (Şekil 1) çevrim boyunca basınç ve sıcaklıktaki değişimlere maruz kalır. Emme zamanı boyunca yağ filmi çok düşük basınç ve sıcaklığa maruz kaldığından yağ filmi içine emilen yakıt miktarı çok azdır. Sıkıştırma stroğu süresince gaz basıncı ve sıcaklığı artar ve yağ filmi pistonun bir kısmı tarafından örtülür. Yağ filminin pistonla örtülü olmayan kısımları ise hidrokarbon emmeye devam edecektir. Aynı şekilde yanma olayı sırasında basınç ve sıcaklık hızlı bir şekilde arttığından, yağ filmi içine hidrokarbon emilmesi devam eder (yağ filminin doyum sınırına ulaşması mümkündür). Emme işlemi alev yağ filmine ulaşana dek devam eder. Hidrokarbonlar yă filmine emilişlerini tamamladıktan sonra bu sefer yağ filmi derinliğince nüfuz etmeye başlarlar.

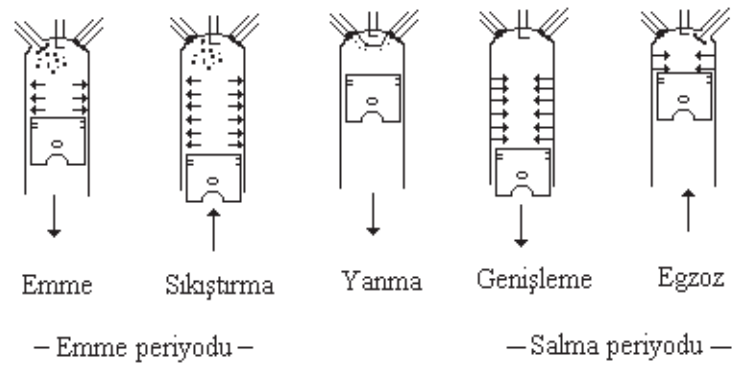

Şekil 1. Yakıtın yağ filmi içerisine emilmesi ve salınması (HC absorbtion/desorbtion mechanism by oil film)

Yakıt buharının emilmesi basınç ve sıcaklıkla değişir. Yağ filmi içine emilen buharın miktarı, daha düşük yağ sıcaklıklarında ve daha yüksek gaz basınçlarında oldukça yüksektir. Yağ sıcaklığı Henry sabitini, silindir içi basınçta her bir bileşenin kısmi basıncını etkiler. Yağ filmi sıcaklığı özellikle silindir gömleği sıcaklığına bağlıdır ki, silindir gömleği sıcaklığı da sanki daimi motor çalışma şartları müddetince izafi olarak değişmeyip aynı kaldığı kabul edilebilir. Bununla birlikte gömlek sıcaklığı yükün artması ile artar ve yağ filmi sıcaklığını etkiler.

Genişleme ve egzoz strokları boyunca yağ filmi piston tarafından açılır. Yağ filmi azalan basınç ve sıcaklığa maruzdur ve yanmış gazlar içindeki hidrokarbon konsantrasyonu hemen hemen sifirdir. Bundan dolayı, hidrokarbonlar yağ filminin dişına doğru salınırlar ve silindir gazları içine yayılırlar. Eğer oksidasyona uğramazlar ve silindirden de çıkabilirlerse yanmamış hidrokarbon emisyonlarına katılırlar.

Yağ filmi için geliştirilen matematik model Henry Kanunu ile difüzyon denklemini içerir.

\subsubsection{Henry Kanunu (Henry's Law)}

Yağ filminin dış yüzeyinde ve yağ filmi içinde erimiş (çözünmüş) yakıt buharı konsantrasyonu, denge halindeki seyreltik çözeltiler için, Henry Kanunu ile ifade edilir. Henry Kanunu, buhar fazındaki yakıtın kısmi basıncı, yağ filmi içerisine emilen yakıtın mol kesri ve Henry sabiti arasında yazılan bir ifadedir, [13].

$$
x_{y a k, y a \check{g}}=\frac{p_{y a k,(g)}}{H}
$$

Gaz halindeki yakıtın kısmi basıncı;

$$
p_{y a k,(g)}=\frac{n_{y a k, s i l} \widetilde{R} T}{V}
$$

şeklinde hesaplanır. Burada; $\mathrm{n}_{\text {yak,sil }}$ silindir içindeki yakıtın mol sayısı, T: sicaklık, $\mathrm{V}$ : silindir hacmi ve $\widetilde{R}$ : üniversal gaz sabitidir [14].

Deneysel sonuçlara göre Henry sabiti $(\mathrm{H})$ ile yă sıcaklığı arasında üssel bir ilişki vardır. Şekil 2'de izo-oktan, propan ve metan için Henry sabiti ile yağ sıcaklığı arasındaki ilişki görülmektedir.

$\mathrm{H}^{*}$; Henry sabiti cinsinden;

$$
H^{*}=H\left(M_{y a \check{g}} / M_{y a k}\right)
$$

$M_{y a g ̆}: \quad$ yağın mol kütlesi, $M_{y a k}:$ yakıtın mol kütlesidir. 
Silindir gömleği sıcaklığına bağlı olan yağ filmi sıcaklığı Henry sabitini, silindir içi basınç da her bir bileşenin kısmi basıncını etkiler. Şekil'2 deki grafiklerden yă̆ filmi sıcaklığı ile $H^{*}$ arasındaki bağıntı;

$$
H^{*} \propto\left(10^{0.0082 T_{y a \check{g}}}\right)
$$

şeklinde olur. Burada $T_{y a \check{g}}$ : cidardaki yă̆ filmi sıcaklığıdır [15].

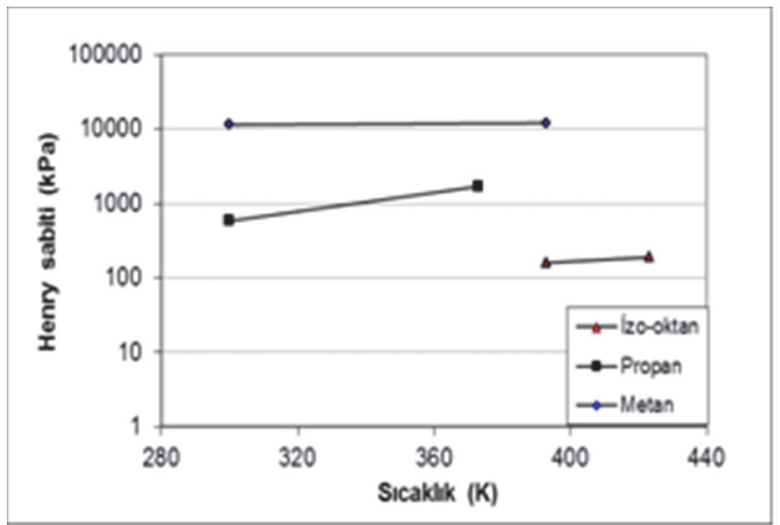

Şekil 2. Farklı yakıtlar için Henry sabiti-yağ sıcaklığı değişimi $[12,15]$ (Variation of Henry's constant-oil film temperature for different fuels)

\subsubsection{Difüzyon Denklemi (Diffusion Equation)}

Yukarıda izah edilen yağ filmi içerisine yakıtın emilip salınması, yağ yüzeyindeki konsantrasyonun ani bir şekilde değişmesinden dolayı, tek boyutlu yakıt difüzyonu problemi olarak davranış gösterir. Yağ filmi Şekil 3'te gösterildiği gibi silindir ekseni yönünde 180 eşit parçaya bölünmüş ve y ekseni yönünde her bir düğüm noktasından diğerine olan difüzyon ihmal edilmiştir [10].

Nümerik çözüm sadece $\mathrm{x}$ ekseni doğrultusunda yapılmaktadır. Bununla birlikte gerçek motor çalışma şartlarında y ekseni doğrultusunda da hücreler arası geçiş söz konusudur. Fakat bu tip geçişlerin modellenmesindeki zorluk ve belirsizlik nedeniyle y yönündeki difüzyon dikkate alınmamıştır.

Şekil 3'teki koordinat sisteminin kullanılmasıyla yağ filmi içindeki yakıtın konsantrasyonu $\mathrm{c}(\mathrm{x}, \mathrm{t})$, difüzyon eşitliğinin kullanımıyla silindir cidarına doğru olan mesafenin ve zamanın bir fonksiyonu olarak belirlenir.

Difüzyon eşitliği;

$$
\frac{\partial c}{\partial t}=D \frac{\partial^{2} c}{\partial x^{2}}
$$

c: yağ filmi içine (tek bir hücre için) emilen yakıt miktarının o hücre içindeki yağ miktarına oranı, yani konsantrasyon, D: yağ filmi içerisinde ilerleyen yakıtın difüzyon katsayısı, x: yağ filmi yüzeyinden silindir cidarına doğru olan mesafe, t: zaman terimidir.

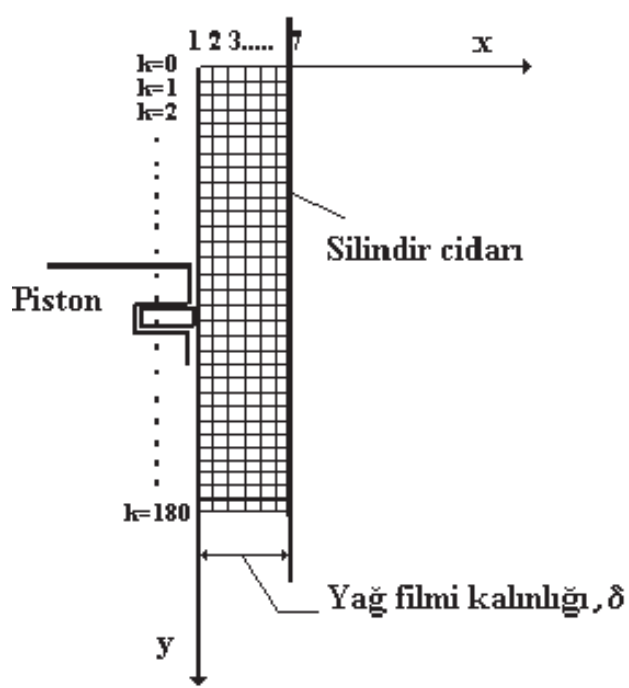

Şekil 3. Yağ filmi boyunca oluşturulan gridlerin şematik gösterimi [10]. (Meshing of oil film)

Sınır şartlart:

i. $\mathrm{c}(\mathrm{x}, 0)=0 \quad \mathrm{t}=0$ anında bütün noktalardaki konsantrasyonlar sifirdir.

ii. $\frac{\partial c}{\partial x}(\delta, t)=0 \quad$ silindir duvarında konsantrasyonun

konuma göre değişimi tüm $\mathrm{t}$ adımlarında sifirdır.

iii. $\mathrm{c}(0, \mathrm{t})=\mathrm{F}(\mathrm{t}) \quad$ silindir gazları ile yağ filmi yüzeyi arasındaki sınır şartı. Henry Kanunundan bulunacak olan konsantrasyon değeridir [16,17].

Burada birinci sınır şartı tüm noktalarda sıfır olarak verilebildiği gibi (başlangıçta yağ filmi hiç yakıt ihtiva etmiyor demektir) çevrim tekrarlanmak suretiyle hesaplanacak olan değerler de başlangıç sınır şartı olarak kullanılabilir. Üçüncü sınır şartındaki F(t) bilinen bir fonksiyondur ve silindir gazları ile yağ filmi yüzeyi arasında Henry Kanunu uygulanmak suretiyle bulunur.

Sıv1-gaz arayüzü için daha önce yazılan Henry Kanunu;

$$
x_{y a k, y a \check{g}}=\frac{p_{y a k,(g)}}{H}=\frac{p}{H}\left(\frac{p_{y a k,(g)}}{p}\right)=\frac{p}{H} Y
$$

şeklinde yazılabilir. 
Xyak,yağ: yağ içindeki yakıtın molar oranı, $\mathrm{p}_{\text {yak,(g): }}$ silindir gazlarındaki yakıtın kısmi basıncı, H: yağ içinde erimeyen yakıt için Henry sabiti, p: gaz karışımının toplam basıncı, Y: gaz karışımı içindeki yakıtın molar oranıdır.

$\mathrm{n}_{\text {yağ ve }} \mathrm{n}_{\text {yak,yağ }}$ sırasıyla yağ filminin ve yă̆ filmi içine emilen yakıtın mol sayıları, $n_{\text {yak }(\mathrm{g})}$ ve $n_{\text {dolgu0 }}$ da sırasıyla gaz fazındaki yakıtın ve diğer tüm karışımın (yakıt+hava+artık gazlar) mol sayıları olmak üzere bu ifadeler (5) nolu eşitlikte yerlerine yazılırlarsa;

$$
\frac{n_{y a k, y a \check{g}}}{n_{y a \check{\mathrm{g}}}+n_{y a k, y a \check{g}}}=\frac{p}{H} \cdot \frac{n_{y a k(g)}}{n_{d o \lg u 0}}
$$

eşitliği elde edilir. Yağ filmi içerisindeki yakıtın mol sayısının yağa göre çok az olacağı ve dolayısı ile ihmal edilebileceği kabulü ile eşitlik

$$
\frac{n_{y a k, y a \breve{g}}}{n_{y a \breve{\mathrm{g}}}} \cong \frac{p}{H} \cdot \frac{n_{y a k(g)}}{n_{d o \lg u} 0}
$$

şeklinde yazılabilir.

Önceki eşitlikte mol sayıları yerlerine yazılırsa;

$$
\begin{gathered}
\frac{m_{y a k, y a \breve{g}} / M_{y a k}}{m_{y a \breve{\mathrm{g}}} / M_{y a \check{\mathrm{g}}}}=\frac{p}{H} \cdot \frac{m_{y a k(g)} / M_{y a k}}{m_{d o \lg u 0} / M_{d o \lg u 0}} \\
\frac{m_{y a k, y a \check{g}}}{m_{y a \breve{\mathrm{g}}}}=\frac{p}{H} \cdot \frac{m_{y a k(g)}}{m_{d o \lg u 0}} \frac{M_{d o \lg u 0}}{M_{y a k}} \frac{M_{y a k}}{M_{y a \check{\mathrm{g}}}} \\
=\frac{p}{H} \cdot \frac{m_{y a k(g)}}{m_{d o \lg u 0}} \frac{M_{d o \lg u 0}}{M_{y a \check{g}}}
\end{gathered}
$$

Burada;

$$
H^{*}(t)=H(t)\left(\frac{M_{y a \check{\mathrm{g}}}}{M_{y a k}}\right) \text { ve } Y_{m}(t)=\frac{m_{y a k(g)}}{m_{d o \lg u 0}}
$$

$\mathrm{Y}_{\mathrm{m}}(\mathrm{t})$ gaz fazındaki yakıtın kütlesel oranı, $\mathrm{p}(\mathrm{t})$ silindir basincı ve;

$$
K(t)=\frac{M_{d o \lg u 0}}{H(t) \cdot M_{y a \breve{\mathrm{g}}}}=\frac{M_{d o \lg u 0}}{H^{*}(t) \cdot M_{y a k}}
$$

olmak üzere üçüncü sınır şartı;

$$
F(t)=c(0, t)=\frac{m_{y a k, y a \breve{g}}}{m_{y a \breve{g}}}=p(t) \cdot Y_{m}(t) \cdot K(t)(8)
$$

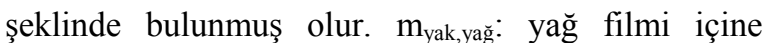

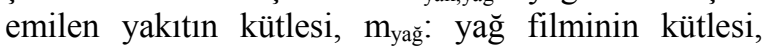

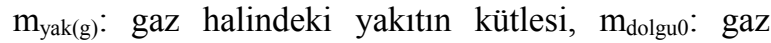
halindeki toplam kütle (yakıt+hava+artık gaz), $\mathrm{M}_{\text {yağ: }}$ : yağın mol kütlesi, $\mathrm{M}_{\text {yak}}$ : yakıtın mol kütlesi, $\mathrm{M}_{\text {dolgu0 }}$ : silindir gazlarının mol kütlesidir.

Bir çevrim boyunca $\mathrm{p}(\mathrm{t}), \mathrm{Y}_{\mathrm{m}}(\mathrm{t}), \mathrm{K}(\mathrm{t})$ değerlerinin değişimi termodinamik çevrim çıktılarına bağlıdır ve bulunmaları burada ele alınmamıştır. Dolayısıyla Eş.(8)'ten pistonun her konumunda yağ filmi yüzeyindeki konsantrasyon değeri hesaplanabilir. Pistonun ÜÖN'dan itibaren $60^{\circ}$ hareket ettiğini düşünelim. Henry Kanunu bize piston $60^{\circ}$ hareket ettikten sonra elde edilen $c(0, t)=F(t)$ yüzey konsantrasyonu değerinin piston blokajından serbest kalan 60 hücre için de eşit olduğunu söyler.

Difüzyon denklemi sonlu fark metodunun kullanımıyla nümerik olarak çözülür. Sonlu fark metodlarından açık çözüm (explicit) metodu kullanılır.

Difüzyon denklemi;

$$
\frac{\partial c}{\partial t}=D \frac{\partial^{2} c}{\partial x^{2}}
$$

I. türev için ileri sonlu fark, II. türev için merkezi sonlu fark kullanılırsa;

$$
\begin{aligned}
& \frac{c_{i}{ }^{k+1}-c_{i}}{\Delta t}=D\left(\frac{c^{k}{ }_{i+1}-2 c^{k}{ }_{i}+c^{k}{ }_{i-1}}{\Delta x^{2}}\right) \\
& c_{i}{ }^{k+1}=c_{i}{ }^{k}+D \frac{\Delta t}{\Delta x^{2}}\left(c^{k}{ }_{i+1}-2 c^{k}{ }_{i}+c^{k}{ }_{i-1}\right)
\end{aligned}
$$

şeklinde bir sonlu fark denklemi elde edilir. Burada i indisi $\mathrm{x}$ yönündeki ilerlemeyi, $\mathrm{k}$ indisi zaman boyutunda ilerlemeyi gösterir. Denklemin çözümünün doğru kabul edilebilir olması için denklemin uygunluk ve kararlılık şartlarını sağlaması gerekmektedir. Mesela $2000 \mathrm{~d} /$ dak için zaman artımı $\Delta t=8,333.10^{-5}$ s olur ve $\Delta x$ derinlik artımı da $0.5 \mu m$ seçilirse, $\quad \gamma=\frac{D \Delta t}{\Delta x^{2}}=0.0166$ olarak hesaplanır. Böylece $\quad \gamma \prec 1 / 2$ kararlılık şartı sağlanmış olur. 180x6, 180x8, 180x9, ..... 180x13 gibi farkl1 grid sayılarında program çalıştırılmış ve sonuçlarda yaklaşık \%5,83 lük bir hata gözlenmiştir.

$\Delta \mathrm{t}: 2000 \mathrm{~d} /$ dak'da çalışan motorun 1 KMA'sına karşılık gelen zaman dilimidir. $\mathrm{Bu}$ da şu şekilde hesaplanmaktadır.

$$
\Delta t=\frac{2000}{60}=33,33 \frac{\mathrm{dev}}{s}=\frac{1}{33,33} \frac{s}{\mathrm{dev}}=0,03 \frac{\mathrm{s}}{\mathrm{dev}}
$$


2000 dev/dak'da çalışan bir motorun bir krank mili devri 0,03 saniyede gerçekleşiyor. 1 devri krankın 360 derecelik dönüşünde gerçekleştiğine göre $1 \mathrm{KMA}$ saniye cinsinden $8,333 \cdot 10^{-5} \mathrm{~s}$ eder.

$$
\Delta t=0,03 \frac{s}{d e v}=\frac{0,03}{360}=8,33 \cdot 10^{-5} \frac{s}{K M A}
$$

Herhangi bir $\mathrm{K}$ adımında, o adımdaki yağ filmi hücresi içerisindeki ortalama konsantrasyon değeri $\mathrm{c}_{\text {ort }}(\mathrm{K})$ ile gösterilirse;

$$
c_{\text {ort }}(K)=\sum_{i=1}^{N} \frac{c_{i}}{N}
$$

formülü ile verilebilir. $c_{i}$ : $x$ doğrultusunda her bir noktanın konsantrasyonu, N: nokta sayısını göstermektedir.

Üniform yağ filmi kalınlığında ve sabit yağ yoğunluğunda silindir cidarı üzerinde strok boyunca oluşan yağ kütlesi;

$$
m_{y a \breve{\mathrm{g}}}=\rho_{y a \breve{\mathrm{g}}} \delta_{y a \breve{\mathrm{g}}} \pi D H
$$

olarak tariflenir. Tek bir hücreye ait yağ kütlesi ise;

$$
\Delta m_{y a \breve{\mathrm{g}}}=\rho_{y a \breve{\mathrm{g}}} \delta_{y a \breve{\mathrm{g}}} \pi D \Delta y
$$

şeklindedir. Tek bir hücre içerisine emilen yakıt miktarı da;

$$
c(0, t)=F(t)=\frac{\Delta m_{y a k}}{\Delta m_{y a \check{g}}}
$$

eşitliğinin kullanımıyla

$$
\Delta m_{y a k}=F(t) \cdot \Delta m_{y a \breve{g}}
$$

şeklinde hesaplanır. Benzer şekilde tüm düğüm noktaları için aynı işlemler tekrarlanır. Nihayet, her düğüm noktasında en son hesap edilen yakıt kütleleri toplanmak suretiyle yağ filmi içinde o anda bulunan toplam yakıt miktarı hesaplanmış olur.

Yağ filmi içine emilen yakıt miktarının silindir içi gazların basıncına, silindir içinde kalan yakıt miktarına ve Henry sabitine, difüzyon katsayısına, motor devrine ve yağ filmi kalınlığına bağlı olduğu görülür.

\section{Difüzyon Katsayılarının Hesabı}

Difüzyon katsayıları aşağıdaki eşitliğe [18] göre hesaplanmıştır.

$$
\begin{aligned}
& D=1,33 \cdot 10^{-11} \frac{T_{o} \mu_{o}\left(\frac{10,2}{V_{A}}-0,791\right)}{V_{A}^{0,71}} \\
& V_{A}=0,285 \cdot V_{c}^{1,048}
\end{aligned}
$$

Yağın viskozitesi $\left(\mu_{0}\right)$ Walter eşitliğinden hesaplanır, [19];

$\log _{10} \log _{10}\left(\mu_{o} / \rho_{o}+0,7\right)=8,17-3,16 \cdot \log _{10}\left(T_{o}\right)$

Eşitlikte geçen yağın yoğunluk değeri referans sicaklıktaki yoğunluk değeri baz alınarak hesaplanmıştır.

$$
\rho\left(T_{o}\right)=\rho\left(T_{o_{0}}\right)-0,63\left(T_{o}-T_{o_{0}}\right)
$$

Yukarıdaki denklemlerde; D: Difüzyon katsayısı $\left(\mathrm{m}^{2} / \mathrm{s}\right), \mathrm{M}_{\mathrm{o}}$ : Yağın mol kütlesi $(\mathrm{g} / \mathrm{mol}), \mathrm{T}_{\mathrm{o}}$ : Yağ sıcaklığı $(\mathrm{K}), \mathrm{V}_{\mathrm{A}}$ : Yakıtın molar hacmi $\left(\mathrm{cm}^{3} / \mathrm{mol}\right), \mathrm{V}_{\mathrm{c}}$ : Yakıtın kritik molar hacmi $\left(\mathrm{cm}^{3} / \mathrm{mol}\right), \mu_{0}$ : Yağın viskozitesi $(\mathrm{g} / \mathrm{ms}), \rho_{\mathrm{o}}$ : Herhangi bir sıcaklıktaki yağın yoğunluğu $\left(\mathrm{g} / \mathrm{cm}^{3}\right), T_{o_{0}}$ : Referans sicaklık $(288,5 \mathrm{~K})$, $\rho\left(T_{o_{0}}\right)$ : Referans sicaklıktaki yağ yoğunluk değeri $\left(894 \mathrm{~kg} / \mathrm{m}^{3}\right)$.

Yakıtların kritik molar hacmi değerleri izo-oktan için $468 \mathrm{~cm}^{3} / \mathrm{mol}$, LPG için $239,4 \mathrm{~cm}^{3} / \mathrm{mol}$ ve metan için $99,2 \mathrm{~cm}^{3} / \mathrm{mol}$ dür.

Tablo 3'te 424,59 K duvar sıcaklığı için hesaplanmış viskozite ve difüzyon katsayısı değerleri verilmiştir. Duvar sıcaklığı değeri rejim halindeki bir motorun eksenel sıcaklık dağılımlarının ortalaması alınarak bulunmuştur, [13].

Tablo 3. Viskozite ve difüzyon katsayısı değerleri (424,59 K duvar sıcaklığı için) (Values of viscosity and diffusion coefficients $\left(\mathrm{T}_{\text {wall }}=424,59 \mathrm{~K}\right)$ )

\begin{tabular}{c|c|c|c|c|}
\hline $\begin{array}{c}\text { TDUVAR } \\
(\mathbf{K})\end{array}$ & $\begin{array}{c}\mu_{\mathbf{0}} \\
(\mathbf{g} / \mathbf{m ~ s})\end{array}$ & $\begin{array}{c}\boldsymbol{D}_{\text {izo-oktan }} \\
\left(\mathbf{m}^{2} / \mathbf{s}\right)\end{array}$ & $\begin{array}{c}\boldsymbol{D}_{\text {metan }} \\
\left(\mathbf{m}^{2} / \mathbf{s}\right)\end{array}$ & $\begin{array}{c}\boldsymbol{D}_{\mathbf{L P G}} \\
\left(\mathbf{m}^{\mathbf{2}} / \mathbf{s}\right)\end{array}$ \\
\hline $424,59 \mathrm{~K}$ & 3,81 & $9,13.10^{-10}$ & $3,95.10^{-9}$ & $1,62.10^{-9}$ \\
\hline
\end{tabular}

\section{MODEL SONUÇLARI ve TARTIŞMA (RESULTS AND DISCUSSION)}

Sonuçlar hesaplanmadan önce kullanılan termodinamik modelin doğruluğu test edilmiştir. Bunun için literatürde benzer şekilde silindir içi basınç ve sıcaklığın hesaplandığı bir programdan faydalanılmıştır, [20]. Bu doğrulamadan sonra izooktan, LPG ve metan için yağ filmi tarafindan emilen ve salınan HC miktarları motor devri, sıkıştırma oranı, giriş basıncı ve hava fazlalık katsayısına göre hesaplanmıştır. 
İzo-oktan, LPG ve metan için elde edilen silindir içi basınç değişimleri Șekil 4'te gösterilmiștir.

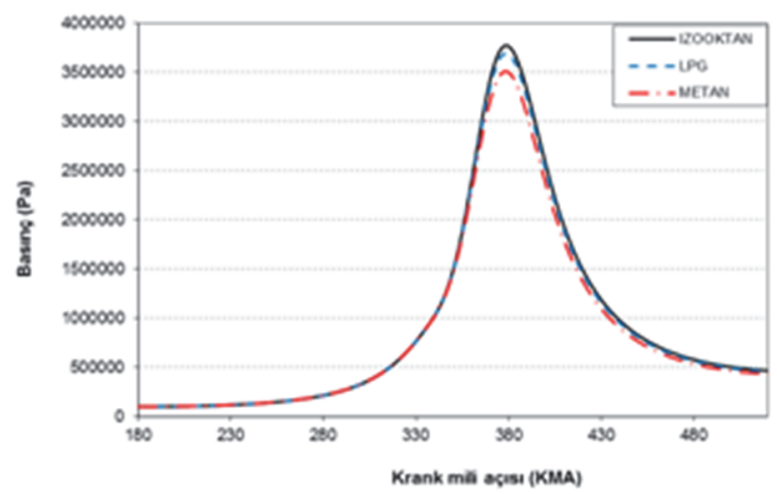

Şekil 4. Silindir içi basınç değişimleri (pressure variations in cylinder)

Şekil 5'te bir çevrim boyunca silindir içine alınan yakıt miktarı 3 farklı yakıt için gösterilmiştir. Silindir içine yakıt girişi emme supabı kapanana kadar (214 KMA) devam etmektedir. 335-405 KMA aras1 değerlerde yanma olmakta ve yakıt miktarı yanma reaksiyonuna bağlı olarak yanarak azalmaktadır. Silindirlere stokimetrik oranda $\mathrm{Y} / \mathrm{H}$ karışımı alındığ 1 için her bir yakıt için silindirlere alınan yakıt miktarları farklı olmaktadır.

Şekil 6'da yağ filmi tarafından emilen yakıt buharı miktarlarının krank mili açısıyla değişimi gösterilmiştir. Emilme işleminin silindir içi maksimum basınca kadar devam ettiği görülmektedir. Hem silindir içerisine alınan en yüksek yakıt miktarı, hem de yağ filmi tarafindan emilen en yüksek HC miktarı izo-oktan da olmuștur. Bunun sebebi izooktanda Henry sabitinin LPG ve metana göre çok daha düşük değerde olmasıdır.

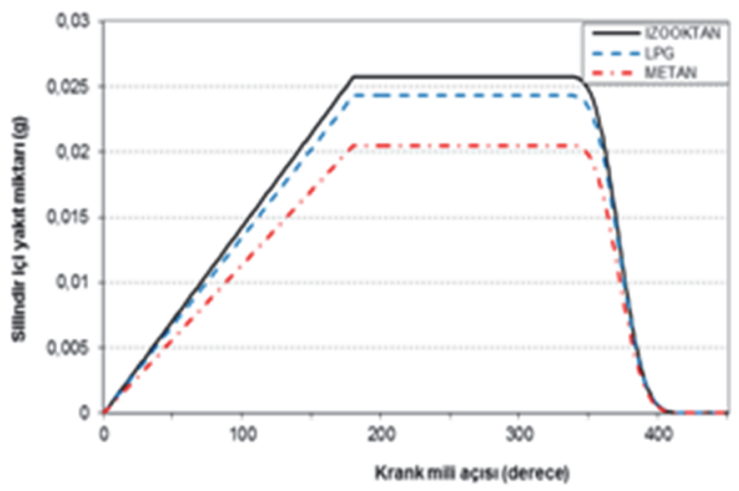

Şekil 5. Bir çevrim boyunca silindir içerisine alınan yakıt miktarları (Fuel quantities entered to the cylinder along a cycle)

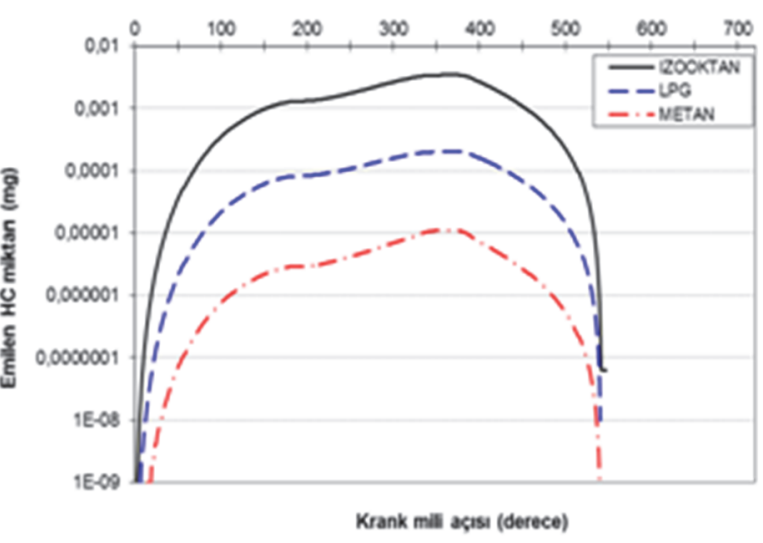

Şekil 6. Farklı yakıtlar için yağ filmi tarafindan emilen $\mathrm{HC}$ miktarı (HC amount absorbed by the oil film for different fuels)

Şekil 7'de yağ filmi tarafından salınan HC miktarları gösterilmiştir. Emilme işlemi çevrim başlangıcından silindir içi maksimum basınç değerine kadar devam etmektedir. Basıncın azalmaya başlamasıyla birlikte yağ filmi içerisindeki hidrokarbonlar silindir içerisine doğru difüze olmaya başlarlar. Salınım işlemi maksimum basınç değeri ile 540 KMA arasında gerçekleşir. $540 \mathrm{KMA}$ dan sonra silindir içerisinde kalan yakıt miktarı çok azaldığından, silindir içi basınç değeri hemen hemen sabit kaldığından ve Henry sabiti artmaya başladığından dolayı yağ filminden herhangi bir salınma görülmemektedir. Emilme işleminde olduğu gibi salınma işleminde de Henry Kanunu ve difüzyon katsayısının önemi büyüktür. Yine burada da yakıtlar içerisinde salınma en fazla izo-oktanda, en düşük metanda görülmektedir.

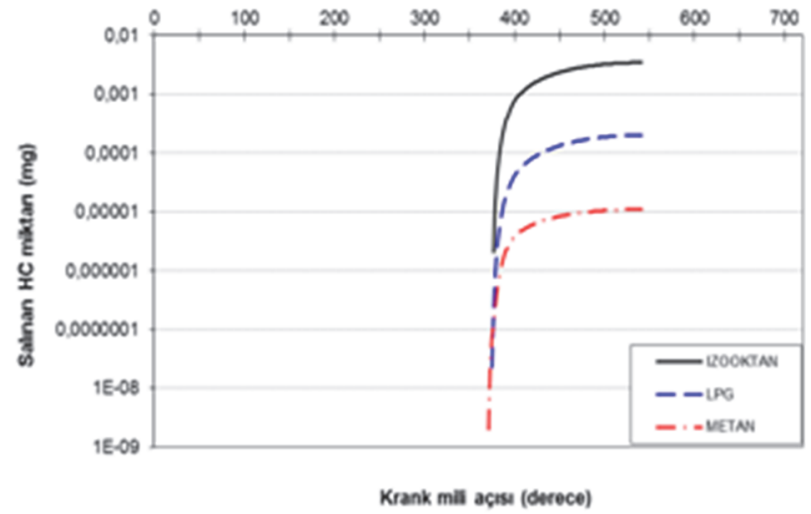

Şekil 7. Farklı yakıtlar için ya ̆̆ filmi tarafindan salınan HC miktar1 (HC amount desorbed by the oil film for different fuels)

Bundan sonraki kısımda parametrik inceleme yapılırken tek bir yakıt seçilmiş ve değiştirilen parametrenin etkisi bu yakıt üzerinde gözlemlenmiştir. Böylece grafiklerin daha sade ve anlaşılır olması sağlanmıştır. Parametredeki değişimin diğer yakıtlar üzerinde de benzer etkiyi göstermesi beklenmelidir. 
Şekil 8 ve 9'da izo-oktan yakıtı ile çalışmada devir sayısına bağlı olarak yağ filmi tarafından emilen ve salınan HC miktarlarındaki değişim gösterilmiştir. Grafiklerde görüldüğü gibi düşük devir sayılarında emilen ve salınan HC miktarları artmaktadır. Bunun sebebi çevrimin daha uzun sürmesi nedeniyle yakıt buhar1-yağ ikilisinin daha uzun süre bir arada bulunmasıdır. Dolayısıyla daha fazla miktarda yakıt buharı (HC) yağ filmince emilir ve yine daha fazla miktarda HC yă̆ filmince salınır.

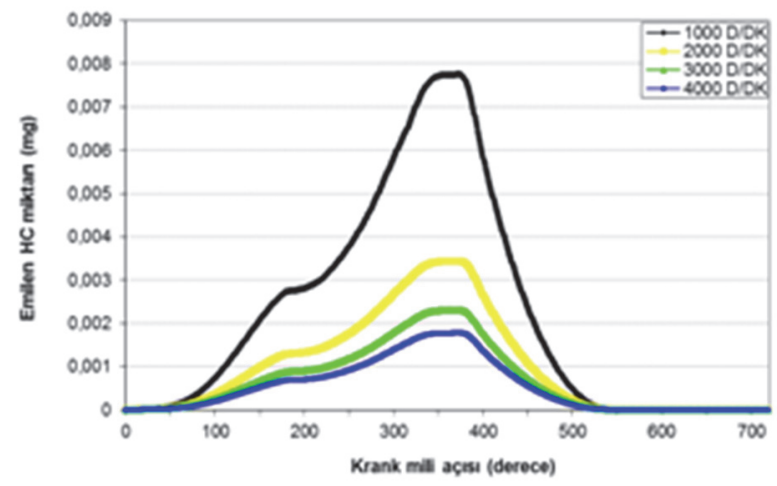

Şekil 8. İzo-oktan için farklı devir sayılarında yağ filmi tarafindan emilen $\mathrm{HC}$ miktarı (HC amount absorbed by the oil film at different engine speeds for iso-octane)

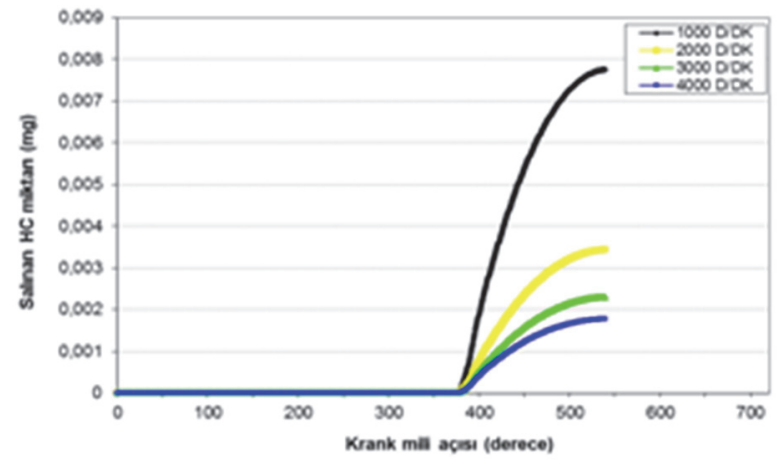

Şekil 9. İzo-oktan için farklı devir sayılarında yă̆ filmi tarafindan salınan $\mathrm{HC}$ miktarı (HC amount desorbed by the oil film at different engine speeds for iso-octane)

Şekil 10 ve 11'de sırasıyla metan için farklı sıkıştırma oranlarında yağ filmi tarafından emilen ve salınan HC miktarları verilmiştir. Grafiklerde görüldüğü gibi sıkıştırma oranı arttıkça yağ filmi tarafından emilen HC miktarları artmaktadır. Bunun temel sebebi sıkıştırma oranının artışıyla birlikte silindir içi basıncın artmasıdır. Basıncın yükselmesi yakıt buharının (HC) yağ filmi içerisine daha kolay yani daha fazla nüfuz etmesi anlamına gelir.

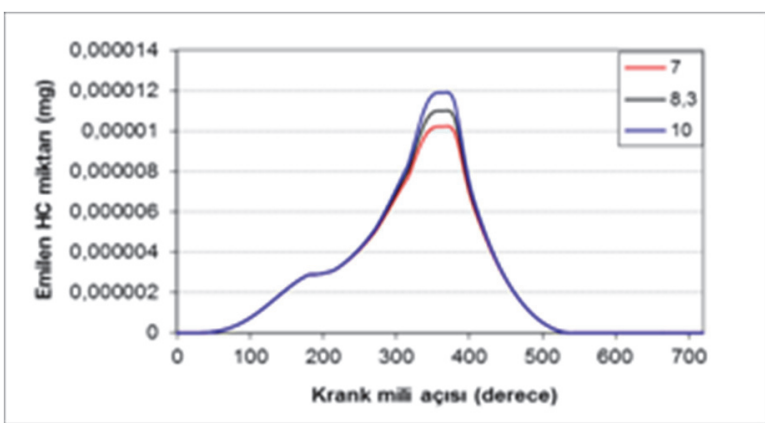

Şekil 10. Metan için farklı sıkıştırma oranlarında $(\varepsilon=7,8.3$ ve 10$)$ yă filmi tarafindan emilen $\mathrm{HC}$ miktarı (HC amount absorbed by the oil film at different compression ratios for methane)

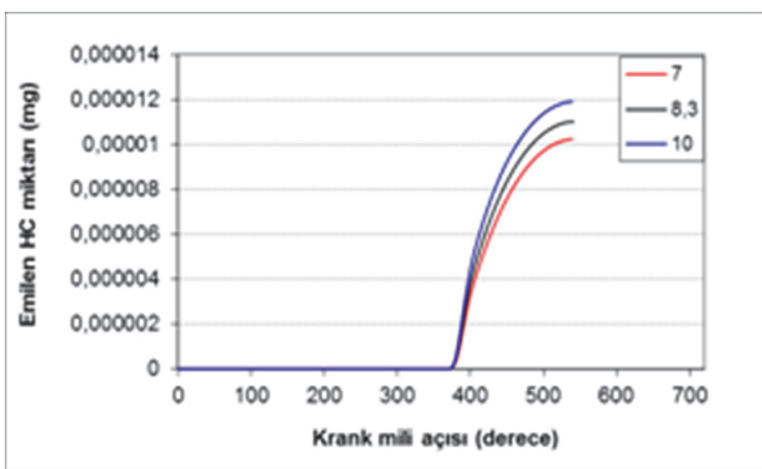

Şekil 11. Metan için farklı sıkıştırma oranlarında yağ filmi tarafından salınan $\mathrm{HC}$ miktarı (HC amount desorbed by the oil film at different compression ratios for methane)

Şekil 12 ve 13'te LPG için farklı giriş basıncı değerlerinin yağ filmince emilen ve salınan HC miktarı üzerindeki etkisi gösterilmektedir. Grafiklerde görüldüğü gibi basınç artışı ile yağ filmi tarafından emilen ve salınan HC miktarlarında artış söz konusudur. Düşük basınç değerlerinde (5) denkleminde de görüldüğü yağ filmi tarafindan emilen yakıt buharı (HC) az olmaktadır.

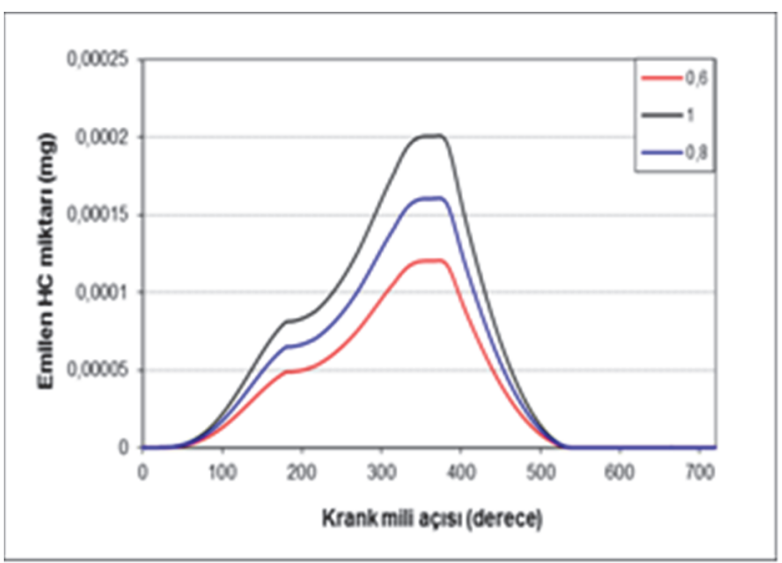

Şekil 12. LPG için farklı giriş basıncı değerlerinde yağ filmi tarafından emilen $\mathrm{HC}$ miktarı (HC amount absorbed by the oil film at different inlet pressure values for LPG) 


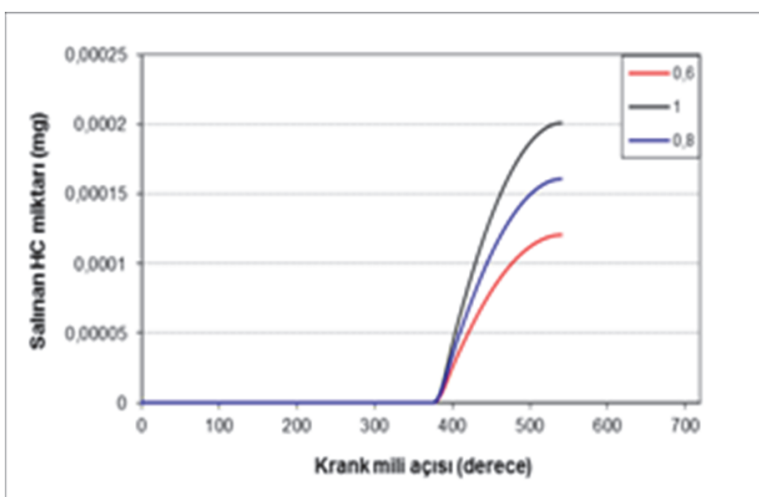

Şekil 13. LPG için farklı hava giriş basıncı değerlerinde yă filmi tarafından salınan $\mathrm{HC}$ miktarının KMA'na göre değişimi (HC amount desorbed by the oil film at different inlet pressure values for LPG)

Şekil 14 ve $15^{\prime}$ te LPG yakıtı için hava fazlalık katsayısının farklı değerlerinin yağ filmi tarafından emilen ve salınan HC miktarı üzerine olan etkisi görülmektedir. Zengin karışımlarda silindir içerisindeki yakıt miktarının artmasıyla birlikte yă filmi tarafından emilen ve salınan $\mathrm{HC}$ miktarlarında da bir artış görülmektedir.

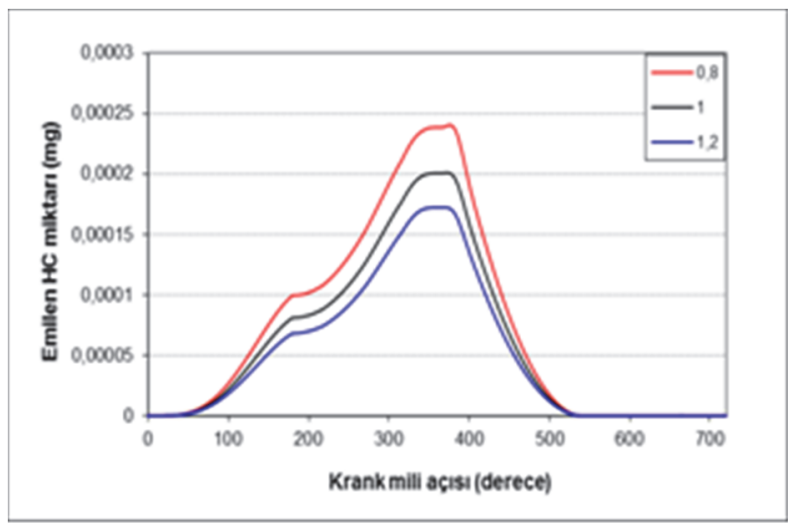

Şekil 14. LPG için farklı hava fazlalık katsayısı değerlerinde yağ filmi tarafindan emilen HC miktarı (HC amount absorbed by the oil film at different excess air ratio values for $\mathrm{LPG}$ )

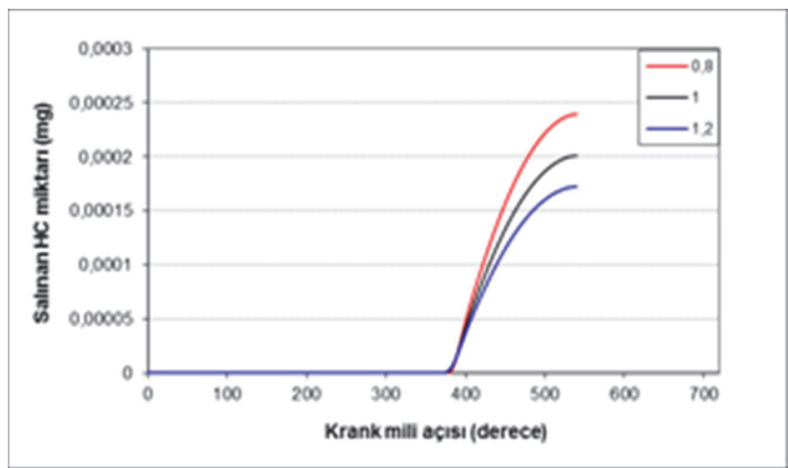

Şekil 15. LPG için farklı hava fazlalık katsayısı değerlerinde yağ filmi tarafından salınan HC miktarı (HC amount desorbed by the oil film at different excess air ratio values for $L P G$ )

\section{SONUÇ (CONCLUSION)}

$\mathrm{Bu}$ çalışmada, benzin (izo-oktan) ile gaz yakıtların (LPG ve metan) yağ filminden kaynaklanan HC emisyonları teorik olarak incelenmiştir. Aşağıdaki sonuçlar elde edilmiştir:

Yağ filmi tarafından yakıt buharının emilme işleminin silindir içi maksimum basınç değerine kadar devam ettiği, daha sonra basıncın azalması ile birlikte yakıt buharının silindir içine doğru difüze olmaya başladığ belirlenmiştir. Yağ filminden olan salınım yaklaşık 540 KMA sına kadar devam etmiş̧tir. 540 KMA dan sonra silindir içerisinde kalan yakıt miktarı çok azaldığından, silindir içi basınç değeri hemen hemen sabit kaldığından ve Henry sabiti artmaya başladığından dolayı yağ filminden herhangi bir salınma görülmemektedir.

İzo-oktan, LPG ve metan arasında yă filmi tarafindan en fazla emilme/salınma olayının gerçekleştiği yakıt izo-oktan olurken, bu olayın en az gerçekleştiği yakıt ise metan olmuştur. Bu farklılığın en önemli nedeni yakıtların sahip olduğu Henry sabiti değerleridir. Aynı silindir cidar sıcaklığı şartlarında, yağ filmi kaynaklı HC emisyonlarına etki derecelerine göre yakıtlar sırasıyla; izo-oktan, LPG ve metan olarak tespit edilmiştir.

Düşük motor devirlerinde HC emisyonlarını arttığ 1 görülmüştür. Bunun nedeni düşük motor devirlerinde yağ filmi yakıt buharı etkileşimine daha uzun süre tanınmasıdır. Artan sıkıştırma oranıyla birlikte silindir içi basınç değerleri de arttığı için emilen/salınan HC emisyonları artmıștır. Giriş basıncı için de aynı durum söz konusudur. Zengin karışım değerlerinde silindir içine alınan yakıt miktarı arttığı için HC emisyonları da doğal olarak artış göstermiştir.

\section{TEŞEKKÜR (ACKNOWLEDGEMENTS)}

Bu çalışma, Seçkin Yenice'nin 14.11.2011 tarihinde Uludağ Üniversitesi, Fen Bilimleri Enstitüsünde kabul edilen yüksek lisans tezinin bir bölümüdür.

\section{KAYNAKLAR (REFERENCES)}

1. Hamrin, D.A. and Heywood, J.B., "Modeling of Engine-Out Hydrocarbon Emissions for Prototype Production Engines", SAE, Paper No: 950984, 1995.

2. Dwyer-Joyce, R.S., Green, D.A., Harper, P., Lewis, R., Balakrishnan, S., King, P.D., Rahnejat, H., Howell-Smith, S., "The Measurement of Liner-Piston Skirt Oil Film Thickness by an Ultrasonic Means", SAE, Paper No: 2006-01-0648, 2006.

3. Baba, Y., Suzuki, H., Sakai, Y., Wei, D.L.T., Ishima, T., Obokata T., "PIV/LIF Measurements of Oil Film Behavior on the Piston in IC Engine", SAE, Paper No: 2007-24-0001, 2007. 
4. Dhar, A., Agarwal A.K., Saxena V., "Measurement of Lubricating Oil Film Thickness Between Piston Ring-Liner Interface in an Engine Simulator", SAE, Paper No: 2008-280071, 2008.

5. Kato, M., Fujita, K., Suzuki, H., Baba, Y., Ishima, T., Obokata T., "Analysis of Lubricant Oil Film Behavior on the Piston Surface according with Piston Shapes by means of LIF and PIV", SAE, Paper No: 2009-28-0003, 2009.

6. Korematsu, K., "Effects of Fuel Absorbed in Oil Film on Unburnt Hydrocarbon Emissions from Spark Ignition Engines", JSME International Journal Series II, Cilt 33, No 3, 606-614, 1990.

7. Shenghua, L., Longbao, Z., Keyu, P., Hui, Z., Xiangfeng Y., "Effects of Cylinder Lubrication Oil Film on Hydrocarbon Emissions of SI Engine", SAE, Paper No: 961913, 1996.

8. Yu, S., Yi, H., Cho, H., Kim, M., Min, K., "Modeling of the Dynamic Process of Fuel Absorption/Desorption in the Oil Film in SI Engines", JSME International Journal Series B, Cilt 43, No 4, 570-575, 2000.

9. $\mathrm{Yu}, \mathrm{S} ., \mathrm{Min}, \mathrm{K}$. , "Effects of the Oil and Liquid Fuel Film on Hydrocarbon Emissions in Spark Ignition Engines", Proceedings of the Institution of Mechanical Engineers, Part D: Journal of Automobile Engineering Cilt 216, 759-771, 2002.

10. Karamangil, M.I., Surmen, A., and Gul, Z., "InCylinder Expansion of Ring Crevice and Oil film Hydrocarbons in SI Engines", Energy Conversion and Management, Cilt 45, No 1819, 3109-3126, 2004.
11. Karamangil, M.I., Kaynaklı, O., Sürmen, A., "Parametric Investigation of Cylinder and Jacket Side Convective Heat Transfer Coefficients of Gasoline Engines. Energy Conversion and Management, Cilt 47, 800-816, 2006.

12. Yenice, S., "Mathematical Modelling of $\mathrm{HC}$ Emissions from Oil Film", Master Thesis, Uludag University, 2011.

13. Heywood, J.B., "Internal Combustion Engine Fundementals", McGraw-Hill International Editions, Singapore, 930 s., 1989.

14. Çengel, A.Y. and Bols, M.A., "Thermodynamics an Engineering Approach", McGraw-Hill International Editions, 1990.

15. Hamrin, D.A., "Modeling of Engine-Out HC Emissions for Prototype Production", Master Thesis, Massachusetts Institute of Technology, 1994.

16. Heywood, J.B. and Hochgreb, S., "Measurement of Gasoline Absoption into Engine Lubricating Oil”, SAE, Paper No: 961229, 1996.

17. Schramm, J. and Sorenson, S.C., "A Model for Hydrocarbon Emissions from SI Engines", SAE, Paper No: 902169, 1990.

18. Salazar, V., "Unburned Hydrocarbon Emission Mechanisms in Small Engines", Ph. D. Thesis, Mechanical Engineering, University of Wisconsin - Madison, USA, 2008.

19. Norris, M.G., Hochgreb, S., "Novel Experiment on In-Cylinder Desorption of Fuel from the Oil Layer", SAE, Paper No:941963, 1994.

20. Ferguson C.R., Kirkpatrick A, "Internal Combustion Engines Applied Thermosciences", John \& Wiley Sons Inc, New York, 2001 